\title{
Efeito do tratamento com aditivos químicos e inoculantes bacterianos nas perdas e na qualidade de silagens de cana-de-açúcar ${ }^{1}$
}

\section{André de Faria Pedroso ${ }^{2}$, Luiz Gustavo Nussio ${ }^{3}$, Daniele Rebouças Santana Loures ${ }^{4}$, Solidete de Fátima Paziani ${ }^{5}$, Maurício Scoton Igarasi ${ }^{6}$, Rodrigo Michelini Coelho ${ }^{7}$, Jorge Horii ${ }^{8}$, Armando de Andrade Rodrigues ${ }^{2}$}

\footnotetext{
1 Parte da tese de doutorado do primeiro autor apresentada ao Programa de Pós-Graduação em Ciência Animal e Pastagens da ESALQ/USP de Piracicaba. Projeto financiado pela FAPESP.

2 Embrapa Pecuária Sudeste, C.P. 339 - CEP: 13560-970 - São Carlos, SP.

3 USPIESALQ - Depto. de Zootecnia, C.P. 9 - CEP: 13418-900 - Piracicaba, SP.

4 Vila Gianetti, 21 - Campus UFV - CEP: 36570-000 - Viçosa, MG.

5 APTA/SAA, C.P. 61 - CEP: 15500-000 - Votuporanga, SP.

6 Av. Cascata Dourada, 552 - Novo Horizonte - São Pedro, SP.

7 Rua Pedra Bonita, 1111 - Alto Barroca - CEP: 30430-390 - Belo Horizonte, MG

8 USP/ESALQ - Depto. de Agroindústria, Alimentos e Nutrição.
}

RESUMO - Objetivou-se avaliar a eficácia de aditivos químicos e inoculantes bacterianos na inibição da produção de etanol, na diminuição das perdas de MS e na melhoria da digestibilidade in vitro de silagens de cana-de-açúcar. Foram testados os seguintes tratamentos (doses com base na matéria natural): sem aditivos - controle; UR - uréia $(0,5 ; 1,0 ; 1,5 \%)$; $\mathrm{NaOH}$ - hidróxido de sódio $(1,0 ; 2,0 ; 3,0 \%)$; PROP - propionato de cálcio $(0,05 ; 0,1 ; 0,2 \%)$; BENZ - benzoato de sódio $(0,05 ; 0,1 ; 0,2 \%)$; SORB - sorbato de potássio $(0,015 ; 0,03 ; 0,045 \%)$; PLA - Lactobacillus plantarum $\left(1 \times 10^{6} \mathrm{ufc} / \mathrm{g}\right) ; \mathrm{BUCH}-$ Lactobacillus buchneri $(3,64 \mathrm{x}$ $10^{5} \mathrm{ufc} / \mathrm{g}$ ); PLA/UR $0,5 \%$ - L. plantarum combinado com $0,5 \%$ de uréia; PLA/UR $1,0 \%$ - L. plantarum combinado com $1,0 \%$ de uréia. A ensilagem foi realizada em baldes plásticos de $20 \mathrm{~L}$ adaptados com válvulas para eliminação de gases e dispositivo para coleta de efluentes. Os dados foram coletados aos 90 e aos 180 dias após a ensilagem. Nenhum dos aditivos foi capaz de reduzir a concentração de etanol nas silagens. Os tratamentos PROP 0,1\% e PLA causaram aumento no teor de álcool em relação à silagem controle (4,8 e 12,5\% vs 3,8\% da MS, respectivamente). Os tratamentos UR, NaOH, SORB-0,03\%, BUCH, PLA/UR 0,5\% e PLA/UR 1,0\% reduziram a perda total de MS. As silagens tratadas com uréia, hidróxido de sódio, benzoato de sódio e sorbato de potássio $0,045 \%$ apresentaram maior digestibilidade in vitro da MS em comparação à silagem controle.

Palavras-chave: benzoato, hidróxido de sódio, L. buchneri, L. plantarum, propionato, sorbato

\section{Effect of chemical and bacterial additives on losses and quality of sugar cane silages}

\begin{abstract}
The objective of this trial was to evaluate chemical and bacterial additives on inhibition of ethanol production, reduction of DM losses and on in vitro digestibility improvement of sugar cane silages. Treatments were (wet basis): without additive - control; urea - UR - $(0.5 ; 1.0 ; 1.5 \%), \mathrm{NaOH}(1 ; 2 ; 3 \%)$, calcium propionate - PROP - $(0.05$ $0.1 ; 0.2 \%)$, sodium benzoate - BENZ - $(0.05 ; 0.1 ; 0.2 \%)$, potassium sorbate - SORB - $(0.015 ; 0.03 ; 0.045 \%)$, Lactobacillus plantarum - PLA - $\left(1 \times 10^{6} \mathrm{cfu} / \mathrm{g}\right)$, Lactobacillus buchneri - BUCH - $\left(3.64 \times 10^{5} \mathrm{cfu} / \mathrm{g}\right)$, L. plantarum combined with urea $(0.5$ e $1.0 \%)$ - PLA/UR-0.5\% and PLA/UR-1.0\%. Sugar cane was ensiled in 20 L plastic buckets with valves for gas release and a device for effluent collection. Data were collected at 90 and $180 \mathrm{~d}$ after ensiling. None of the additives was effective in reducing ethanol concentration in the silages and PROP- $0.1 \%$ and PLA increased alcohol levels relative to control (4.8 and $12.5 \%$ vs $3.8 \%$ in DM, respectively). The treatments UR, NaOH, SORB-0.03\%, BUCH, PLA/UR-0.5\% and PLA/UR-1.0\% reduced total DM losses. Silages treated with UR, NaOH, BENZ and SORB-0,045\% had higher in vitro DM digestibility than the control silage.
\end{abstract}

Key Words: benzoate, L. buchneri, L. plantarum, propionate, sodium hydroxide, sorbate

\section{Introdução}

A cana-de-açúcar é amplamente utilizada como forragem suplementar de inverno no Brasil e em outros países de clima tropical, sendo utilizada também como principal volumoso em fazendas produtoras de leite e em confinamentos de gado de corte. É uma forrageira com grande potencial de produção de MS e energia por área e permite bom desempenho 
dos animais quando corretamente suplementada com proteínas e minerais (Boin \& Tedeschi, 1993). A cana-deaçúcar mantém seu valor nutritivo durante os meses de inverno, sendo tradicionalmente fornecida fresca aos animais. A ensilagem tem sido utilizada para evitar as operações diárias de corte e transporte da cana e pode colaborar ainda para o aumento da produtividade e da vida útil dos canaviais pela maior eficiência nos cuidados pós-colheita, como capina e fertilização. Serve ainda para evitar a perda total da forragem em casos de incêndio ou de geadas.

Silagens de cana-de-açúcar apresentam, no entanto, intensa atividade de leveduras que convertem açúcares a etanol, dióxido de carbono e água, causando reduções de até $70 \%$ no teor de carboidratos solúveis (CHO's), aumento nos componentes da parede celular e perdas de MS (Alli et al., 1983; Pedroso et al., 2005). Teores de etanol de 8 a $17 \%$ da MS têm sido relatados para cana-de-açúcar ensilada sem o uso de aditivos, resultando em perdas aproximadas de 30\% da MS durante o processo (Kung Jr. \& Stanley, 1982; Pedroso et al., 2005)

As leveduras não são inibidas pelo $\mathrm{pH}$ das silagens, que, na maioria das espécies forrageiras, varia de 3,5 a 6,5 (McDonald et al., 1991). Altas contagens de leveduras causam a deterioração das silagens expostas ao ar durante a estocagem ou após a abertura dos silos, promovendo aumento do $\mathrm{pH}$ e do risco de desenvolvimento de microrganismos patogênicos, como a Listeria monocytogenes (Rotz \& Muck, 1994).

Aditivos químicos e microbianos têm sido utilizados no intuito de evitar o desenvolvimento de leveduras em silagens tradicionais, entretanto, poucos têm sido testados na ensilagem da cana-de-açúcar com vistas ao controle da produção de etanol.

A uréia - quando em contato com a forragem ensilada, é hidrolizada a amônia, que tem efeito inibidor sobre a população de leveduras e mofos - tem se mostrado capaz de reduzir a produção de etanol e as perdas de MS e de CHO's em silagem de cana-de-açúcar (Alli et al., 1983). Em pesquisas realizadas por Lima et al. (2002) e Molina et al. (2002), níveis de 0,5 a 1,5\% de uréia propiciaram bom padrão de fermentação e melhor composição bromatológica, com teores mais elevados de MS associados a menores concentrações de fibra FDA e FDN.

Substâncias fortemente alcalinas também modificam o processo de fermentação das silagens. Silagens de canade-açúcar tratadas com 3 a $4 \%$ de $\mathrm{NaOH}$ apresentaram melhor composição bromatológica, redução acentuada na produção de etanol (5,2\% para $0,9 \%$ da MS), maior teor de ácido lático e maior digestibilidade da MS e resultaram em maior consumo e ganho de peso em comparação a silagens produzidas sem aditivos (Castrillón et al., 1978; Alcántara et al., 1989).

O crescimento de microrganismos pode ser evitado por ácidos orgânicos fracos, como o ácido propiônico (McDonald et al., 1991). Apesar de não haver relatos da avaliação desse ácido na ensilagem da cana-de-açúcar, seu uso mostrou-se eficiente no controle do desenvolvimento de fungos e na melhoria da estabilidade aeróbia de silagens de azevém e milho (Ohyama et al., 1975; Britt et al., 1975). Alguns produtos químicos utilizados como conservantes na indústria alimentícia têm sido testados como aditivos para silagem. Os ácidos sórbico e benzóico inibiram o crescimento de leveduras em testes de laboratório (Woolford, 1975) e o benzoato de sódio combinado à hexamina melhorou a conservação de silagens de capim emurchecido, promovendo redução no número de leveduras e diminuição na perda de CHO's das silagens quando expostas ao ar (Lättemäe \& Lingvall, 1996).

A elevação artificial do número de bactérias homofermentativas produtoras de ácido lático, como o Lactobacillus plantarum, pode reduzir o $\mathrm{pH}$ final, aumentar o conteúdo de ácido lático e diminuir a produção de efluentes e a perda de MS durante a conservação das silagens (McDonald et al., 1991), no entanto, os efeitos sobre a população de leveduras e a estabilidade aeróbia são variáveis (Higginbotham et al., 1998, Driehuis \& Wikselaar, 2000). Por outro lado, inoculantes contendo a bactéria heterofermentativa Lactobacillus buchneri, que converte o ácido lático em ácido acético, 1,2 propanodiol, ácido propiônico, dióxido de carbono e traços de etanol (Oude et al., 2001), têm apresentado eficiência no controle do desenvolvimento de leveduras e no aumento da estabilidade aeróbia das silagens (Ranjit \& Kung Jr., 2000).

Nesta pesquisa, avaliou-se o efeito do tratamento com aditivos químicos (uréia, hidróxido de sódio, benzoato de sódio, sorbato de potássio, propionato de cálcio) e inoculantes bacterianos (L. plantarum, L. buchneri e a combinação de L. plantarum com uréia) no controle da produção de etanol, nas perdas de MS e na qualidade de silagens de cana-de-açúcar.

\section{Material e Métodos}

As silagens experimentais foram produzidas no Setor de Ruminantes do Departamento de Zootecnia da ESALQ/ USP de Piracicaba, SP, utilizando-se cana-de-açúcar variedade RB785148 (13 meses de crescimento; primeiro corte; $22,5^{\circ}$ Brix) colhida com máquina colhedeira de forragem (Mentamit ${ }^{\circledR}$ ) acoplada a um trator e regulada para corte com tamanho médio de partículas de 5 a $10 \mathrm{~mm}$. 
Os aditivos foram aplicados à cana-de-açúcar picada antes da ensilagem, na forma de soluções aquosas, utilizando-se pulverizadores manuais. Os tratamentos avaliados foram (doses com base na matéria natural): sem aditivo; UR - uréia nas doses de 0,5; 1,0 e 1,5\%; $\mathrm{NaOH}$ - hidróxido de sódio nas doses de 1,0; 2,0 e 3,0\%; PROP - propionato de cálcio nas doses de 0,$05 ; 0,1$ e $0,2 \%$; BENZ - benzoato de sódio nas doses de 0,$05 ; 0,1$ e $0,2 \%$; SORB - sorbato de potássio nas doses de 0,015;0,03 e 0,045\%; PLA L. plantarum (ECOSYL ${ }^{\circledR}$, ECOSYL Products Ltd, Cleveland, UK) na dose de $1 \times 10^{6} \mathrm{ufc} / \mathrm{g}$; BUCH - L. buchneri (estirpe NCIMB $40788^{\circledR}$, Biotal Ltd, Cardiff, UK) na dose de $3,64 \times 10^{5}$ ufc/g; PLA/UR 0,5\% - L. plantarum com 0,5\% de uréia; PLA/UR 1,0\% - L. plantarum com 1,0\% de uréia. A uréia foi aplicada utilizando-se $35 \mathrm{~L}$ de solução/t de forragem e o benzoato e o propionato de sódio, utilizando-se $12 \mathrm{~L} \mathrm{de}$ solução/t de forragem. O hidróxido de sódio (solução comercial a 50\%) foi aplicado sem diluição, nas quantidades de 20, 40 e 60 L/t. Os inoculantes L. plantarum e L. buchneri foram pulverizados utilizando-se $1,89 \mathrm{~L}$ de solução/t de forragem.

A forragem foi compactada em silos laboratoriais (baldes de plástico de $20 \mathrm{~L}$ ), em triplicata, em densidade de $450 \mathrm{~kg} / \mathrm{m}^{3}$. Após o enchimento, os minissilos foram fechados com tampas providas de válvulas do tipo Bunsen e pesados. Após a pesagem, as tampas foram vedadas com fita plástica auto-adesiva. No fundo dos baldes, foram colocados $2 \mathrm{~kg}$ de areia seca (separados da silagem por tela fina de plástico e duas camadas de tecido fino de algodão) para quantificação de efluentes. Foram preparados 120 minissilos, correspondentes aos 20 tratamentos, duas datas de abertura $(90$ e 180 dias após a ensilagem) e três repetições. Os minissilos foram pesados no dia da ensilagem e em cada data de abertura. As perdas gasosas foram estimadas pela diferença de peso bruto dos minissilos no dia da ensilagem e nas datas de abertura. A perda total de MS foi calculada como a diferença entre o peso da MS inicial e o peso da MS nas datas de abertura dos minissilos. A variação no peso dos silos contendo apenas a areia, a tela de plástico e o tecido de algodão foi utilizada para estimativa dos efluentes.

Amostras representativas foram retiradas da cana-deaçúcar (antes da ensilagem) e das silagens (em cada data de abertura dos minissilos). As amostras para determinação dos teores de $\mathrm{PB}$, etanol e $\mathrm{pH}$ foram mantidas congeladas $\left(-10^{\circ} \mathrm{C}\right)$ até o dia da análise. Outras amostras foram secas em estufas de ventilação forçada $\left(60^{\circ} \mathrm{C}, 48\right.$ horas $)$, sendo trituradas em moinho estacionário com peneira de malha de $1 \mathrm{~mm}$ e analisadas por espectroscopia de reflectância de infravermelho proximal (NIRS) (Berzaghi et al., 1997) em espectrofotômetro modelo NIRS $5000^{\circledR}$ (NIRSystems, Silver
Spring, MD, USA). O software do equipamento indicou as amostras a serem analisadas pelos métodos tradicionais para inferência da composição do conjunto de amostras.

As concentrações de MS, cinzas e PB foram determinadas segundo AOAC (1990). Os teores de FDA e FDN foram expressos sem cinzas e o teor de lignina foi determinado pela solubilização da celulose com ácido sulfúrico. A FDN foi determinada com sulfito de sódio e sem alfa amilase, de acordo com Van Soest \& Robertson (1985). A digestibilidade in vitro da MS (DIVMS) foi estimada utilizando-se Daisy incubator (ANKON Technology Corporation, Fairport, USA). O etanol e o $\mathrm{pH}$ foram determinados em extratos aquosos produzidos segundo o método descrito por Kung Jr. et al. (1984). O etanol foi analisado em um cromatógrafo a gás (Hewlett Packard 5890 Series II) equipado com detetor de ionização de chama, com coluna ID 2-m $\times 2$-mm com chromosorb 101 (Johns - Manville, Denver, USA) e integrador eletrônico. $\mathrm{O}$ teor de $\mathrm{PB}$ da silagem produzida com uréia (tratamento UR) foi determinado pelo método macro Kjeldahl (AOAC, 1990) em amostras úmidas mantidas congeladas $\left(-10^{\circ} \mathrm{C}\right)$.

O delineamento experimental utilizado foi o inteiramente casualizado, com 20 tratamentos e três repetições, cada uma constituída de dois minissilos. O teor de MS inicial da cana-de-açúcar de cada tratamento foi testado como covariável e, diante da ausência de efeito, foi removido do modelo original. O modelo proposto foi analisado pelo PROC GLM do programa SAS (SAS, 1988) utilizando-se o Método dos Quadrados Mínimos (LSMEANS) para comparação das médias. Foram consideradas significativas as diferenças entre as médias a partir de $\mathrm{P}<0,05$. Aplicou-se o teste $\mathrm{F}$ para contraste a partir do desdobramento dos graus de liberdade.

\section{Resultados e Discussão}

A cana-de-açúcar utilizada para ensilagem apresentou níveis médios de MS $(29,3 \%)$ e PB (4,3\%), teores relativamente altos de FDN (55,3\%), FDA (37,7\%) e lignina $(6,4 \%)$ e DIVMS $(53,6 \%)$ inferior à de 18 variedades de cana-deaçúcar avaliadas por Landell et al. (2002) (58 a 69\%). A concentração de PB na cana-de-açúcar após a adição de 0,5 ; 1,0 e $1,5 \%$ de UR antes da ensilagem atingiu 7,8;10,0 e 19,5\% na MS da forragem, respectivamente.

Os efeitos dos tratamentos foram avaliados considerando a média dos dados obtidos nas duas datas de abertura dos minissilos, visando obter valores representativos de um intervalo mais amplo de estocagem, considerando que o teor de alguns componentes nutritivos e indicadores de perdas de MS podem sofrer pequena 
variação no período de 90 a 180 dias após a ensilagem da cana-de-açúcar (Pedroso et al., 2005).

Os dados de fermentação e de perdas nas silagens dos diversos tratamentos encontram-se na Tabela 1. O teor de etanol observado na silagem controle pode ser considerado baixo, uma vez que os dados da literatura indicam valores entre 5,5 e 15,5\% desse álcool na MS de silagens de canade-açúcar colhidas aos 12 meses de crescimento e ensiladas sem aditivos (Preston et al., 1976; Kung Jr. \& Stanley, 1982). A baixa concentração de etanol pode ser conseqüência da volatilização, que pode resultar em redução de $50 \%$ na concentração do álcool na MS de silagens de cana-deaçúcar no período de 90 a 180 dias de ensilagem (Pedroso et al., 2005). Nenhum dos aditivos foi capaz de reduzir a concentração de etanol das silagens em relação à silagem controle. O uso dos aditivos propionato (PROP-0,1\%) e L. plantarum (PLA) resultou em níveis mais altos de álcool nas silagens (Tabela 1). A concentração de etanol na silagem com PLA foi, aproximadamente, três vezes maior que a da silagem controle e a perda total de MS situou-se entre os níveis mais elevados, de modo que a perda por gases causou aproximadamente $69 \%$ das perdas totais da MS neste tratamento (Tabela 1). A produção de efluentes também se manteve entre os maiores valores observados. O maior teor de etanol desta silagem foi acompanhado pela menor DIVMS, correspondente a uma perda de $23,1 \%$ do valor da digestibilidade da cana fresca. Os teores de FDN, FDA e lignina foram mais elevados e o de MS, praticamente o mais baixo entre todos os tratamentos, assemelhando-se somente ao de PLA/UR-0,5\%. A alta concentração de etanol indica que a inoculação com L. plantarum não controlou o desenvolvimento das leveduras, confirmando a informação da literatura de que apenas a redução do pH não é suficiente para impedir o desenvolvimento desses microrganismos e que o ácido lático tem baixo poder fungicida (McDonald et al., 1991). O resultado está de acordo ainda com o obtido em outros trabalhos nos quais a inoculação com bactérias homofermentativas produtoras de ácido lático foi incapaz de reduzir a população de leveduras em silagens (Bolsen et al., 1992; Ranjit \& Kung Jr., 2000). Higginbothan et al. (1998) constataram que silagem de milho inoculada com L. plantarum $\left(1,5 \times 10^{4} \mathrm{ufc} / \mathrm{g}\right) \mathrm{e}$ $P$. cerevisae $\left(3 \times 10^{5} \mathrm{ufc} / \mathrm{g}\right)$ apresentou teor de etanol duas vezes superior ao da silagem controle $(2,14$ vs $1,04 \%$ da MS) e não teve efeito sobre a população de leveduras.

O uso de propionato (PROP-0,1\%) também aumentou a concentração de etanol na silagem e elevou as perdas de MS na forma de gases e efluentes (Tabela 1), resultando em diminuição acentuada na DIVMS em relação ao material original (44,4 vs 53,6\%). A adição de propionato nas três doses proporcionou, em média, teor de etanol de 6,29\%, redução de 19,3\% na DIVMS e perdas totais de MS de $14,5 \%$, porém, não houve diferença entre as três silagens quanto a essas características. Kung Jr. et al. (2000) constataram diminuição do teor de etanol em silagem de milho tratada com $0,2 \%$ de ácido propiônico tamponado, mas não detectaram efeito para as doses de 0,1 e $0,3 \%$ do ácido. Ranjit \& Kung Jr. (2000) relataram ausência de efeito sobre a população de leveduras com a aplicação de $0,1 \%$ de um produto comercial contendo ácido propiônico tamponado em silagens de milho, porém, esses autores não avaliaram o efeito sobre a produção de etanol.

Os resultados deste experimento sugerem que as concentrações de propionato normalmente utilizadas no tratamento de silagens são insuficientes para o controle de leveduras. Testes de laboratório indicaram que a concentração de ácido propiônico necessária para inibição do desenvolvimento desses microrganismos é de aproximadamente $60 \mathrm{mmol} / \mathrm{L}$ de meio de cultura em pH 4 (Moon, 1983; Woolford, 1975), equivalente a 4,7 g/L de meio de cultura. A concentração máxima de propionato avaliada neste estudo $(0,2 \%)$, escolhida com base na literatura, corresponde a 2,7 $\mathrm{g} / \mathrm{L}$ de água contida na forragem (considerando-se $25 \%$ de MS na silagem), o que pode explicar o fato de o aditivo não ter reduzido a produção de etanol nas silagens.

A inoculação da silagem com L. buchneri (BUCH) não causou diminuição na concentração de etanol, mas reduziu em $56 \%$ a perda total de MS da silagem, embora a produção de efluentes tenha sido $51 \%$ maior em relação à da silagem sem aditivos (Tabela 1). A cana-de-açúcar inoculada com L. buchneri apresentou menor redução na DIVMS durante a ensilagem, quando comparada àquela sem aditivo (10,4 vs 15,3\%). Apesar de não ter sido detectada redução significativa na concentração de etanol, a redução das perdas indica que houve controle no desenvolvimento de leveduras na silagem inoculada com L. buchneri. A aplicação de L. buchneri tem resultado em silagens com 3,6 a 5,0\% de ácido acético na MS (Ranjit \& Kung Jr., 2000; Taylor et al., 2002). Concentração de 2\% de ácido acético na MS, equivalente a 6,7 $\mathrm{g}$ do ácido por litro da fase líquida de uma forragem com $25 \%$ de MS, é suficiente para o controle de leveduras, visto que leveduras são normalmente controladas por concentrações de ácido acético superiores a 5,6 g/L do meio de cultura (94 mmol/L) (Woolford, 1975). Resultados de outros trabalhos de pesquisa indicaram redução na população de leveduras com aplicações de L. buchneri na proporção de $10^{6} \mathrm{ufc} / \mathrm{g}$ de matéria verde (Driehuis et al., 1999; Ranjit \& Kung Jr., 2000). 
Tabela 1 - Parâmetros de fermentação, digestibilidade e perdas em silagens de cana-de-açúcar tratadas com aditivos químicos e inoculantes bacterianos ${ }^{3}$

Table 1 - Fermentation parameters, digestibility, and losses in sugar cane silages treated with chemical additives and bacterial inoculants

\begin{tabular}{|c|c|c|c|c|c|c|}
\hline \multirow[t]{2}{*}{$\begin{array}{l}\text { Tratamento } \\
\text { Treatment }\end{array}$} & $\mathrm{pH}$ & $\begin{array}{l}\text { Etanol } \\
\text { Ethanol }\end{array}$ & $\begin{array}{c}\text { Perda de gases } \\
\text { Gas losses }\end{array}$ & \multirow{2}{*}{$\begin{array}{c}\text { Perda total de MS } \\
\text { Total DM loss } \\
\%\end{array}$} & \multirow{2}{*}{$\begin{array}{c}\text { DIVMS } \\
I V D M D \\
\mathrm{~kg} / \mathrm{t}\end{array}$} & \multirow[t]{2}{*}{$\begin{array}{c}\text { Efluente } \\
\text { Effluent }\end{array}$} \\
\hline & \multicolumn{3}{|c|}{$\% \mathrm{MS}(\% \quad D M)$} & & & \\
\hline $\begin{array}{l}\text { Sem aditivo } \\
\text { Without additive }\end{array}$ & $3,69^{\mathrm{de}}$ & $3,82^{\mathrm{c}}$ & $10,3^{\mathrm{ab}}$ & $18,2^{\mathrm{ab}}$ & $45,4^{\mathrm{e}}$ & $15,1^{\mathrm{c}}$ \\
\hline UR- $0,5 \%$ & $3,67^{\mathrm{de}}$ & $4,20^{\mathrm{c}}$ & $8,10^{\mathrm{bc}}$ & $12,2^{\mathrm{cd}}$ & $50,3^{\mathrm{cd}}$ & $28,5^{\mathrm{ab}}$ \\
\hline UR- $1,0 \%$ & $3,72^{\mathrm{de}}$ & $4,09^{\mathrm{c}}$ & $8,56^{\mathrm{bc}}$ & $7,59^{d}$ & $50,2^{\mathrm{cd}}$ & $32,2^{\mathrm{a}}$ \\
\hline UR-1,5\% & $3,83^{\mathrm{d}}$ & $3,47^{\mathrm{c}}$ & $11,9^{\mathrm{ab}}$ & $6,56^{\mathrm{d}}$ & $49,3^{\mathrm{cd}}$ & $26,0^{\mathrm{ab}}$ \\
\hline $\mathrm{NaOH}-1 \%$ & $4,31^{\mathrm{c}}$ & $2,44^{\mathrm{c}}$ & $6,85^{\mathrm{bc}}$ & $8,91^{\mathrm{d}}$ & $54,8^{b}$ & $6,53^{\mathrm{d}}$ \\
\hline $\mathrm{NaOH}-2 \%$ & $5,08^{b}$ & $2,40^{\mathrm{c}}$ & $4,78^{c}$ & $11,7^{\mathrm{cd}}$ & $65,4^{\mathrm{a}}$ & $5,98^{\mathrm{d}}$ \\
\hline $\mathrm{NaOH}-3 \%$ & $5,78^{\mathrm{a}}$ & $2,44^{\mathrm{c}}$ & $4,93^{c}$ & $12,1^{\mathrm{cd}}$ & $67,3^{\mathrm{a}}$ & $6,41^{\mathrm{d}}$ \\
\hline BENZ0,05\% & $3,60^{\mathrm{de}}$ & $3,70^{\mathrm{c}}$ & $9,60^{\mathrm{bc}}$ & $18,1^{\mathrm{ab}}$ & $48,2^{\mathrm{d}}$ & $22,8^{b}$ \\
\hline BENZ- $0,1 \%$ & $3,66^{\mathrm{de}}$ & $2,52^{\mathrm{c}}$ & $9,83^{b}$ & $16,9^{\mathrm{b}}$ & $49,8^{\mathrm{cd}}$ & $26,9^{a b}$ \\
\hline BENZ- $0,2 \%$ & $3,83^{\mathrm{d}}$ & $2,03^{\mathrm{c}}$ & $5,94^{\mathrm{bc}}$ & $14,0^{\mathrm{bc}}$ & $51,8^{\mathrm{c}}$ & $25,8^{b}$ \\
\hline PROP- $0,05 \%$ & $3,68^{\mathrm{de}}$ & $6,81^{b c}$ & $12,2^{\mathrm{ab}}$ & $13,6^{\mathrm{bc}}$ & $45,7^{\mathrm{de}}$ & $25,0^{b}$ \\
\hline PROP- $0,1 \%$ & $3,65^{\mathrm{de}}$ & $7,30^{\mathrm{b}}$ & $12,1^{\mathrm{ab}}$ & $20,1^{\mathrm{ab}}$ & $44,4^{\mathrm{e}}$ & $28,7^{\mathrm{ab}}$ \\
\hline PROP- $0,2 \%$ & $3,71^{\mathrm{de}}$ & $4,77^{\mathrm{bc}}$ & $10,3^{\mathrm{ab}}$ & $15,8^{\mathrm{bc}}$ & $46,0^{\text {de }}$ & $23,1^{b}$ \\
\hline SORB-0,015\% & $3,68^{\mathrm{de}}$ & $3,05^{\mathrm{c}}$ & $12,7^{\mathrm{ab}}$ & $15,4^{\mathrm{bc}}$ & $47,1^{\mathrm{de}}$ & $14,8^{\mathrm{c}}$ \\
\hline SORB- $0,03 \%$ & $3,71^{\mathrm{de}}$ & $1,79^{c}$ & $7,75^{\mathrm{bc}}$ & $11,2^{\mathrm{cd}}$ & $48,1^{\mathrm{de}}$ & $11,4^{\mathrm{cd}}$ \\
\hline SORB- $0,045 \%$ & $3,59^{\mathrm{de}}$ & $2,87^{\mathrm{c}}$ & $8,17^{\mathrm{bc}}$ & $17,0^{\mathrm{b}}$ & $50,6^{\mathrm{cd}}$ & $21,6^{\mathrm{bc}}$ \\
\hline BUCH & $3,52^{\mathrm{e}}$ & $1,95^{\mathrm{c}}$ & $8,93^{\mathrm{bc}}$ & $8,05^{\mathrm{d}}$ & $48,0^{\mathrm{de}}$ & $22,8^{b}$ \\
\hline PLA & $3,58^{\mathrm{de}}$ & $12,5^{\mathrm{a}}$ & $14,8^{\mathrm{a}}$ & $21,5^{\mathrm{a}}$ & $41,2^{\mathrm{f}}$ & $29,9^{\mathrm{ab}}$ \\
\hline PLA/UR-0,5\% & $3,74^{\mathrm{de}}$ & $6,17^{b c}$ & $13,7^{\mathrm{ab}}$ & $12,7^{\mathrm{c}}$ & $45,6^{\mathrm{de}}$ & $26,3^{\mathrm{ab}}$ \\
\hline PLA/UR-1,0\% & $3,71^{\mathrm{de}}$ & $6,29^{b c}$ & $10,1^{b}$ & $11,4^{\mathrm{cd}}$ & $45,3^{\mathrm{e}}$ & $14,8^{\mathrm{c}}$ \\
\hline
\end{tabular}

${ }^{1}$ Média das observações aos 90 e 180 dias de ensilagem.

2 Tipo de aditivo utilizado na ensilagem (doses com base na matéria natural): sem aditivo; UR - uréia 0,5; 1,0 e 1,5\%; NaOH - hidróxido de sódio 1,0;2,0 e 3,0\%; BENZ - benzoato de sódio 0,05; 0,1 e 0,2\%; PROP - propionato de cálcio 0,05; 0,1 e $0,2 \%$; SORB - sorbato de potássio 0,$015 ; 0,03$ e $0,045 \%$; BUCH - L. buchneri 3,64 × $10^{5} \mathrm{ufc} / \mathrm{g}$; PLA - L. plantarum $1 \times 10^{6} \mathrm{ufc} / \mathrm{g}$; PLA/UR - L. plantarum com 0,5 ou $1,0 \%$ de uréia.

DIVMS = digestibilidade in vitro da MS.

Letras diferentes na mesma coluna indicam diferença significativa $(P<0,05)$.

${ }_{1}^{1}$ Mean values for 90 and 180 days after ensiling.

2 Type of additive used at ensiling (wet basis): without additive; UR - urea 0.5, 1.0 and 1.5\%; $\mathrm{NaOH}$-sodium hydroxide 1, 2 and $3 \%$; BENZ-sodium benzoat $0.05,0.1$ and $0.2 \%$; $P R O P$ - calcium propionate $0.05,0.1$ and $0.2 \%$;SORB - potassium sorbate 0.015, 0.03 amd 0.045\%; BUCH - Lactobacillus buchneri (3.64 x $\left.10^{5} \mathrm{cfu} / \mathrm{g}\right) ; \mathrm{PLA}-\mathrm{Lactobacillus} \mathrm{plantarum}\left(1 \times 10^{6} \mathrm{cfu} / \mathrm{g}\right)$; PLA/URL. plantarum plus urea (0.5 and $1.0 \%)$.

IVDMD = in vitro DM digestibility.

Means within a column followed by different letters differ $(P<0.05)$.

As perdas de MS das silagens tratadas com uréia (UR-1,0\% e UR-1,5\%) foram as mais baixas neste experimento, embora as concentrações de etanol tenham sido semelhantes às obtidas na silagem sem aditivo e os níveis de produção de efluentes tenham situado entre os mais altos (Tabela 1). Os teores de FDN e FDA nestes tratamentos sofreram pequenos acréscimos durante a conservação das silagens e foram aproximadamente $10 \%$ inferiores aos da silagem controle (Tabela 2). De forma coerente com a diminuição na fração fibrosa, os valores de DIVMS dessas silagens sofreram incrementos de 8,6 a 10,6\% em relação à digestibilidade da silagem controle. Em geral, a adição de uréia resultou em silagens com pH adequado à conservação (McDonald et al., 1991) e com teores de PB que indicam concentração do nitrogênio aplicado na silagem decorrente da perda de outros componentes.

A adição de uréia juntamente com bactérias homoláticas (PLA/Ur-0,5\% e PLA/Ur-1,0\%) não reduziu o pH das silagens a níveis mais baixos que os das silagens tratadas apenas com uréia e resultou em produções de etanol e perdas totais de MS iguais às das silagens tratadas com as doses correspondentes de uréia na forma exclusiva (Tabela 1), indicando que não houve benefício da ação conjunta dos aditivos, a não ser a redução de efluentes na silagem tratada com L. plantarum e uréia 1\% (PLA/Ur-1,0\%).

As silagens tratadas com $\mathrm{NaOH}$ apresentaram teores de etanol semelhantes ao obtido na silagem sem aditivo, porém, as perdas totais de MS ocorreram nos níveis mais baixos observados neste trabalho, apesar de as silagens terem apresentado $\mathrm{pH}$ superior ao nível máximo considerado adequado à estabilização de forragens ensiladas (Tabela 1). As produções de efluentes nesta silagem foram as menores e as DIVMS as maiores. Em média, as silagens tratadas com $\mathrm{NaOH}$ foram $46 \%$ mais digeríveis que a silagem sem aditivo e 2,2 a 25,6\% mais digeríveis que a cana-de-açúcar fresca. De forma coerente com a maior digestibilidade das silagens, a adição de $\mathrm{NaOH}-2 \%$ e $\mathrm{NaOH}-3 \%$ resultou em silagens com menores concentrações de FDN, FDA e lignina (Tabela 2). A capacidade do $\mathrm{NaOH}$ em romper a estrutura e solubilizar componentes da parede celular (Mattos, 1987) deve ter 
Tabela 2 - Composição química de silagens de cana-de-açúcar tratadas com aditivos químicos e inoculantes bacterianos ${ }^{1}$ Table 2- Chemical composition of sugar cane silages treated with chemical additives and bacterial inoculants

\begin{tabular}{|c|c|c|c|c|c|c|}
\hline $\begin{array}{l}\text { Tratamento }{ }^{2} \\
\text { Treatment }\end{array}$ & $\begin{array}{l}\text { MS final } \\
\text { Final } D M\end{array}$ & $\begin{array}{l}\mathrm{PB} \\
C P\end{array}$ & $\begin{array}{l}\text { FDN } \\
N D F\end{array}$ & $\begin{array}{l}\mathrm{FDA} \\
A D F\end{array}$ & $\begin{array}{l}\text { Lignina } \\
\text { Lignin }\end{array}$ & $\begin{array}{c}\text { Cinzas } \\
\text { Ash }\end{array}$ \\
\hline Treatment & $\%$ & \multicolumn{5}{|c|}{$\% \mathrm{MS}(\% D M)$} \\
\hline Sem aditivo & $25,4^{\mathrm{d}}$ & 4,34 ef & $64,5 \mathrm{~b}$ & $44,3^{\mathrm{bc}}$ & $7,86^{\mathrm{c}}$ & $6,97^{\mathrm{c}}$ \\
\hline \multicolumn{7}{|l|}{ Without additive } \\
\hline UR- $0,5 \%$ & $26,7^{\mathrm{c}}$ & $9,87^{\mathrm{d}}$ & $57,7^{\mathrm{cd}}$ & $39,7^{\mathrm{d}}$ & $7,03^{\mathrm{d}}$ & $6,07^{\mathrm{d}}$ \\
\hline UR- $1,0 \%$ & $27,3^{\mathrm{bc}}$ & $16,6^{b}$ & $58,2^{\mathrm{cd}}$ & $39,9^{\mathrm{d}}$ & $7,14^{\mathrm{d}}$ & $6,01^{\mathrm{d}}$ \\
\hline UR- $1,5 \%$ & $26,4^{\mathrm{c}}$ & $22,7^{\mathrm{a}}$ & $56,8^{\mathrm{d}}$ & $40,6^{\mathrm{d}}$ & $7,55^{\mathrm{cd}}$ & $5,50^{\mathrm{de}}$ \\
\hline $\mathrm{NaOH}-1 \%$ & $27,5^{\mathrm{bc}}$ & $3,89^{\mathrm{fg}}$ & $55,4^{\mathrm{d}}$ & $40,8^{\mathrm{d}}$ & $7,04^{\mathrm{d}}$ & $9,12^{\mathrm{b}}$ \\
\hline $\mathrm{NaOH}-2 \%$ & $27,3^{b c}$ & $2,87^{\mathrm{g}}$ & $47,3^{\mathrm{e}}$ & $36,7^{\mathrm{e}}$ & $5,94^{\mathrm{e}}$ & $11,0^{\mathrm{a}}$ \\
\hline $\mathrm{NaOH}-3 \%$ & $29,2^{\mathrm{a}}$ & $2,82^{\mathrm{g}}$ & $44,8^{\mathrm{e}}$ & $36,4^{\mathrm{e}}$ & $5,91^{\mathrm{e}}$ & $11,2^{\mathrm{a}}$ \\
\hline BENZ0,05\% & $26,0^{\text {cd }}$ & $3,91^{\mathrm{fg}}$ & $60,9^{c}$ & $41,8^{\mathrm{cd}}$ & $7,40^{\mathrm{cd}}$ & $6,13^{\mathrm{d}}$ \\
\hline BENZ- $0,1 \%$ & $26,5^{\mathrm{c}}$ & $3,64^{\mathrm{fg}}$ & $60,0^{\mathrm{cd}}$ & $41,5^{\mathrm{cd}}$ & $7,22^{\mathrm{d}}$ & $5,49^{\mathrm{de}}$ \\
\hline BENZ- $0,2 \%$ & $27,5^{\mathrm{bc}}$ & $3,36^{\mathrm{fg}}$ & $57,1^{\mathrm{d}}$ & $41,0^{\mathrm{cd}}$ & $7,10^{\mathrm{d}}$ & $5,28^{\mathrm{e}}$ \\
\hline PROP- $0,05 \%$ & $25,1^{\mathrm{d}}$ & $4,43^{\text {ef }}$ & $63,7^{b c}$ & $43,8^{\mathrm{bc}}$ & $7,92^{b c}$ & $6,81^{\mathrm{cd}}$ \\
\hline PROP- $0,1 \%$ & $24,8^{\mathrm{d}}$ & $4,34^{\mathrm{ef}}$ & $65,8^{\mathrm{ab}}$ & $45,3^{b c}$ & $8,31^{b c}$ & $6,44^{\mathrm{cd}}$ \\
\hline PROP- $0,2 \%$ & $26,4^{\mathrm{c}}$ & $3,84^{\mathrm{fg}}$ & $63,8^{\mathrm{bc}}$ & $44,1^{b c}$ & $7,98^{b c}$ & $6,80^{\mathrm{cd}}$ \\
\hline SORB- $0,015 \%$ & $28,0^{\mathrm{b}}$ & $4,00^{f}$ & $62,7^{b c}$ & $43,1^{\mathrm{c}}$ & $7,51^{\mathrm{cd}}$ & $6,95^{\mathrm{c}}$ \\
\hline SORB- $0,03 \%$ & $28,8^{\mathrm{ab}}$ & $4,19^{\mathrm{ef}}$ & $61,6^{\mathrm{bc}}$ & $42,8^{\mathrm{cd}}$ & $7,38^{\mathrm{cd}}$ & $6,83^{\mathrm{cd}}$ \\
\hline SORB- $0,045 \%$ & $26,1^{\mathrm{cd}}$ & $3,64^{\mathrm{fg}}$ & $59,5^{\mathrm{cd}}$ & $40,3^{\mathrm{d}}$ & $6,94^{\mathrm{d}}$ & $5,46^{\mathrm{de}}$ \\
\hline $\mathrm{BUCH}$ & $26,5^{\mathrm{c}}$ & $4,09^{\mathrm{ef}}$ & $60,6^{\mathrm{c}}$ & $41,0^{\mathrm{cd}}$ & $7,38^{\mathrm{cd}}$ & $5,91^{\mathrm{de}}$ \\
\hline PLA & $23,7^{\mathrm{e}}$ & $5,14^{\mathrm{e}}$ & $68,9^{\mathrm{a}}$ & $48,7^{\mathrm{a}}$ & $9,19^{\mathrm{a}}$ & $6,61^{\mathrm{cd}}$ \\
\hline PLA/UR-0,5\% & $24,5^{\mathrm{de}}$ & $10,9^{\mathrm{d}}$ & $63,6^{\mathrm{bc}}$ & $45,4^{b}$ & $8,25^{\mathrm{bc}}$ & $6,26^{\mathrm{cd}}$ \\
\hline PLA/UR- $1,0 \%$ & $26,4^{\mathrm{c}}$ & $15,4^{\mathrm{c}}$ & $62,8^{\mathrm{bc}}$ & $45,7^{\mathrm{b}}$ & $8,50^{\mathrm{b}}$ & $6,65^{\mathrm{cd}}$ \\
\hline
\end{tabular}

${ }^{1}$ Média das observações aos 90 e 180 dias de ensilagem.

2 Tipo de aditivo utilizado na ensilagem (doses com base na matéria natural): sem aditivo; UR - uréia 0,5; 1,0 e 1,5\%; NaOH - hidróxido de sódio 1,0;2,0 e 3,0\%; BENZ - benzoato de sódio 0,05; 0,1 e $0,2 \%$; PROP - propionato de cálcio 0,$05 ; 0,1$ e $0,2 \%$; SORB - sorbato de potássio 0,$015 ; 0,03$ e $0,045 \%$; BUCH - L. buchneri 3,64 × $10^{5} \mathrm{ufc} / \mathrm{g}$; PLA - L. plantarum $1 \times 10^{6} \mathrm{ufc} / \mathrm{g} ;$ PLA/UR - L. plantarum com 0,5 ou $1,0 \%$ de uréia. DIVMS = digestibilidade in vitro da MS.

Letras diferentes na mesma coluna indicam diferença significativa $(P<0,05)$.

${ }^{1}$ Mean values for 90 and 180 days after ensiling

2 Type of additive used at ensiling (wet basis): without additive; UR- urea 0.5, 1.0 and 1.5\%; $\mathrm{NaOH}$-sodium hydroxide 1,2 and $3 \%$; BENZ- sodium benzoat $0.05,0.1$ and $0.2 \%$; PROP- calcium propionate 0.05, 0.1 and 0.2\%;SORB - potassium sorbate 0.015, 0.03 amd 0.045\%; BUCH-Lactobacillus buchneri (3.64 x 105 cfu/g); PLA - Lactobacillus plantarum (1 x 106 cfu/g); PLA/UR-

L. plantarum plus urea (0.5 and $1.0 \%)$.

IVDMD = in vitro $D M$ digestibility.

Means within a column followed by different letters differ $(P<0.05)$.

compensado o aumento na concentração de fibra, em decorrência do consumo de CHO durante a fermentação em silagens de cana-de-açúcar (Pedroso et al., 2005). Reduções significativas na concentração de etanol de silagens de cana-de-açúcar tratadas com $\mathrm{NaOH}$ em concentrações de 3 a 4\% na MS foram relatadas por Castrillón et al. (1978) e Alcántara et al. (1989), o que não ocorreu neste experimento. Ressalta-se, no entanto, que, apesar de seus efeitos positivos, o $\mathrm{NaOH}$ tem sofrido restrições de uso na ensilagem, pelos riscos inerentes à sua manipulação, ao meio ambiente e à redução na vida útil das máquinas.

A adição de benzoato de sódio (BENZ) nas silagens não reduziu a concentração de etanol e as perdas totais de MS nas silagens, mas o teor de FDN foi inferior e a DIVMS superior à da silagem sem aditivo $(\mathrm{P}<0,05)$ (Tabela 1$)$. As perdas por efluentes foram acentuadas $(25,2 \mathrm{~kg} / \mathrm{t}$ em média) e maiores que as obtidas na silagem sem aditivo. São escassas as pesquisas com aditivos contendo benzoato de sódio; Lättemäe \& Lingvall (1996) observaram efeito positivo da aplicação de $0,15 \%$ de benzoato, por meio de um aditivo contendo também nitrito de sódio e hexamina, em silagens de azevém emurchecido. Neste experimento, verificou-se efeito benéfico sobre a conservação das silagens, que apresentou maior teor de carboidratos solúveis (68 vs 11\% da MS), resultando em silagens com MS mais elevada (40 x 36\%) em comparação à silagem sem aditivo.

Nenhuma das doses de sorbato de potássio (SORB) foi capaz de reduzir o teor de etanol nas silagens, todavia, a aplicação desse aditivo na dose de $0,03 \%$ reduziu a perda de MS e, na dose $0,045 \%$, melhorou a DIVMS em relação à silagem sem aditivo. A produção de efluentes das silagem tratadas com esse aditivo foram semelhantes à obtida na silagem sem aditivo $(\mathrm{P}>0,05)$. Apesar de as doses de sorbato não terem reduzido a produção de etanol neste experimento, Weinberg et al. (1989) constataram redução de $47 \%$ no teor de álcool ( 8,30 vs $15,7 \%$ da MS) e menor perda de CHO's em silagem de polpa úmida de laranja tratada com $0,05 \%$ de sorbato de potássio. Esses pesquisadores afirmaram que o aditivo não causou redução significativa na contagem de leveduras e que o efeito, portanto, deve ter sido apenas de inibição da atividade, e não de eliminação desses microrganismos. 


\section{Conclusões}

Apesar de o baixo conteúdo em etanol da silagem sem aditivo ter evitado a detecção de efeito dos aditivos na redução do álcool nas silagens, o uso de aditivos constitui ferramenta útil para redução das perdas de MS e obtenção de silagens de cana-de-açúcar com melhor valor nutritivo.

\section{Literatura Citada}

ALCÁNTARA, E.; AGUILERA, A.; ELLIOT, R. et al. Fermentation and utilization by lambs of sugarcane harvested fresh and ensiled with and without NaOH. 4. Ruminal kinetics. Animal Feed Science and Technology, v.23, p.323-331, 1989.

ALLI, I.; FAIRBAIRN, R.; BAKER, B.E. The effects of ammonia on the fermentation of chopped sugarcane. Animal Feed Science and Technology, v.9, p.291-299, 1983.

ASSOCIATION OF OFFICIAL ANALYTICAL CHEMISTRY AOAC. Official methods of analysis. 15.ed. Arlington, 1990. v. $1,1117 \mathrm{p}$.

BERZAGHI, P.; COZZI, G.; ANDRIGHETTO, I. The use of near infrared analysis for in situ studies. Journal of Dairy Science, v. 80, p.3263-3270, 1997

BOIN, C.; TEDESCHI, L.O. Cana-de-açúcar na alimentação de gado de corte. In: SIMPÓSIO SOBRE NUTRIÇÃO DE BOVINOS, 5., 1993, Piracicaba. Anais... Piracicaba: Fundação de Estudos Agrários Luiz de Queiroz, 1993. p.107-126.

BOLSEN, K.K.; LIN, C.; BRENT, B.E. et al. Effect of silage additives on the microbial succession and fermentation process of alfalfa and corn silages. Journal of Dairy Science, v.75, p.3066-3083, 1992.

BRITT, D.G.; HUBER, J.T.; ROGERS, A.L. Fungal growth and acid production during fermentation and refermentation of organic acid treated corn silages. Journal of Dairy Science, v. 58 p.532-539, 1975 .

CASTRILLÓN, M.V.; SHIMADA, A.S.; CALDERÓN, F.M. Manipulacion de la fermentacion en ensilajes de caña de azucar y su valor alimenticio para borregos. Técnica Pecuária en México, v.35, p.48-55, 1978.

DRIEHUIS, F.; ELFERINK, S.J.W.H.O.; SPOELSTRA, S.F. Anaerobic lactic acid degradation during ensilage of whole crop maize inoculated with Lactobacillus buchneri inhibits yeast growth and improves aerobic stability. Journal of Applied Microbiology, v.87, p.583-594, 1999.

DRIEHUIS, F.; WIKSELAAR, P.G. The occurrence and prevention of ethanol fermentation in high-dry-matter grass silage. Journal of Science of Food and Agriculture, v.80, p.711718,2000

HIGGINBOTHAM, G.E.; MUELLER, S.C.; BOLSEN, K.K. et al. Effects of inoculants containing propionic acid bacteria on fermentation and aerobic stability of corn silage. Journal of Dairy Science, v.81, p.2185-2192, 1998.

KUNG JR., L.; STANLEY, R.W. Effect of stage of maturity on the nutritive value of whole-plant sugarcane preserved as silage. Journal of Animal Science, v.54, p.689-696, 1982.

KUNG JR., L.; GRIEVE, D.B.; THOMAS, J.W. et al. Added ammonia or microbial inocula for fermentation and nitrogenous compounds of alfalfa ensiled at various percents of dry matter. Journal of Dairy Science, v.67, p.299-306, 1984.

KUNG JR., L.; ROBINSON, J.R.; RANJIT, N.K. et al. Microbial populations, fermentation end-products, and aerobic stability of corn silage treated with ammonia or a propionic acid-based preservative. Journal of Dairy Science, v.83, p.1479-1486, 2000.

LANDELL, M.G.A.; CAMPANA, M.P.; RODRIGUES, A.A. et al. A variedade IAC86-2480 como nova opção de cana-de-açúcar para fins forrageiros: manejo de produção e uso na alimentação animal. Campinas: Instituto Agronômico de Campinas, 2002. 36p. (Boletim Técnico, 193).

LÄTTEMÄE, P.; LINGVALL, P. Effect of hexamine and sodium nitrite in combination with sodium benzoate and sodium propionate on fermentation and storage stability of wilted and long cut grass silage. Swedish Journal of Agricultural Research, v.26, p.135-146, 1996.

LIMA, J.A.; EVANGELISTA, A.R.; ABREU, J.G. et al. Silagem de cana-de-açúcar (Saccharum officinarum L.) enriquecida com uréia ou farelo de soja (compact disc). In: REUNIÃO DA SOCIEDADE BRASILEIRA DE ZOOTECNIA, 39., 2002, Recife. Anais... Recife: Sociedade Brasileira de Zootecnia, 2002. (CD-ROM).

MATTOS, W.R.S. Utilização de bagaço de cana-de-açúcar na alimentação de ruminantes. In: CONGRESSO PAULISTA DE AGRONOMIA, 6., 1987, Piracicaba. Anais... Piracicaba: Fundação de Estudos Agrários Luiz de Queiroz, 1987. p.99-112.

McDONALD, P.; HENDERSON, A.R.; HERON, S.J.E. The biochemistry of silage. 2.ed. Marlow: Chalcomb Publication, 1991. 340p.

MOLINA, L.R.; FERREIRA, D.A.; GONÇALVES, L.C. et al. Padrão de fermentação da silagem de cana-de-açúcar (Saccharum officinarum L.) submetida a diferentes tratamentos (compact disc). In: REUNIÃO DA SOCIEDADE BRASILEIRA DE ZOOTECNIA, 39., 2002, Recife. Anais... Recife: Sociedade Brasileira de Zootecnia, 2002. (CD-ROM).

MOON, N.J. Inhibition of the growth of acid tolerant yeasts by acetate, lactate and propionate and their synergistic mixtures. Journal of Applied Bacteriology, v.55, p.453-460, 1983.

OHYAMA, Y.; MASAKI, S.; HARA, S. Factors influencing aerobic deterioration of silages and changes in chemical composition after opening silos. Journal of Science of Food and Agriculture, v.26, p.1137-1147, 1975.

OUDE EELFERINK, S.J.H.W.; KROONEMAN, J.; GOTTSCHAL, J.C. et al. Anaerobic conversion of lactic acid to acetic acid and 1,2-propanediol by Lactobacillus buchneri. Applied and Environmental Microbiology, v.67, p.125-132, 2001.

PEDROSO, A.F.; NUSSIO, L.G.; PAZIANI, S.F. et al. Fermentation and epiphytic microflora dynamics in sugar cane silage. Scientia Agricola, v.62, p.427-432, 2005.

PRESTON, T.R.; HINOJOSA, C.; MARTINEZ, L. Ensiling of sugar cane with ammonia molasses and mineral acids. Tropical Animal Production, v.1, p.120-126, 1976.

RANJIT, N.K.; KUNG JR., L. The effect of Lactobacillus buchneri, Lactobacillus plantarum, or a chemical preservative on the fermentation and aerobic stability of corn silage. Journal of Dairy Science, v.83, p.526-535, 2000.

ROTZ, C.A.; MUCK, R.E. Changes in forage quality during harvest and storage. In: FAHEY JR., G.C.; COLLINS, M.; MERTENS, D.R. et al. (Eds.) Forage quality, evaluation and utilization. Madison: ASA, CSSA, SSSA, 1994. p.828-868.

STATISTICAL ANALYSIS SYSTEM - SAS. SAS/STAT user's guide. Cary: 1988. (CD-ROM).

TAYLOR, C.C.; RANJIT, N.J.; MILLS, J.A. et al. The effect of treating whole-plant barley with Lactobacillus buchneri 40788 on silage fermentation, aerobic stability, and nutritive value for dairy cows. Journal of Dairy Science, v.85, p.1793-1800, 2002.

Van SOEST, P.J.; ROBERTSON, J.B. Analysis of forages and fibrous foods. Ithaca: Cornell University, 1985. 202p.

WEINBERG, Z.G.; ASHBELL, G.; HOREY, B. The effect of sorbic acid on loss reduction during storage of orange peels. Journal of Science of Food and Agriculture, v.46, p.253-258, 1989.

WOOLFORD, M.K. Microbial screening of food preservatives, cold sterilants and specific antimicrobial agents as potential silage additives. Journal of Science of Food and Agriculture, v.26, p.229-237, 1975 .

Recebido: 10/03/06 Aprovado: 01/12/06 